\title{
AVALIAÇÃO DA SAÚdE DE TRABALHADORES PORTUÁRIOS DO PORTO DE PARANAGUÁ/PR
}

HEALTH EVALUATION OF PORT WORKERS OF PARANAGUA PORT / PR

\author{
Arlete Ana Motter ${ }^{1}$ \\ Jacqueline Emiko Nishizuka \\ Tatiane de Souza Gonçalves \\ Alessandra Madalena Garcia ${ }^{2}$ \\ Karen Tiemi Matsuzaki ${ }^{3}$
}

\section{Resumo}

O objetivo deste estudo foi conhecer o trabalho do estivador, bem como correlacionar as condicionantes da atividade portuária com o processo saúde/doença. Esta pesquisa possui caráter exploratório, cuja análise de dados foi quantitativa. Desenvolveu-se de dezembro de 2009 até maio de 2010 no Porto de Paranaguá/PR. Participaram 100 estivadores do sexo masculino, que responderam ao questionário elaborado para a pesquisa e aos questionários Nórdico (Pinheiro, Tróccoli e Carvalho, 2002) e de Risco de Lombalgia (Couto, 1995). A análise de dados evidencia precariedade das condições de trabalho, insatisfação salarial e exposição a diversos riscos, sendo $80 \%$ com risco altíssimo de lombalgia e dores em diversas partes do corpo. Em contrapartida, demonstram gostar do trabalho que realizam, por permitir certa flexibilidade.

Palavras-chave: trabalho portuário, processo saúde/doença, estivadores.

\author{
Abstract \\ The aim of this study was to characterize and understand the work of the stevedore, and \\ correlate the constraints of the port work with the process health /disease. This research has an \\ exploratory character, whose data analysis was quantitative. It took place between December \\ 2009 and May 2010 at the Port of Paranaguá, state of Paraná. Participated 100 male stevedores \\ (dockers) who responded to the survey prepared for the research, the Nordic Survey (Pinheiro, \\ Artigo recebido em 08 de agosto de 2012 e aprovado em 05 de novembro de 2012. \\ 1 Professora Adjunto I da Universidade Federal do Paraná- Setor Litoral. E-mail: arlete.motter@uol.com.br \\ 2 Fisioterapeutas formadas pela Universidade Federal do Paraná- Setor Litoral. \\ 3Acadêmica do Curso de Fisioterapia da UFPR - Litoral \\ Divers@ Revista Eletrônica Interdisciplinar/Matinhos/Vol.5, n.2, p.1-136/jul./dez./2012
}


Tróccoli and Carvalho, 2002) and the Risk of Low Back Pain Survey (Couto, 1995). The data analysis highlights the precarious working conditions, salary dissatisfaction, and exposure to various risks, being $80 \%$ with very high risk of low back pain and other pains in various body parts. On the other hand, they show fondness for the work they do, for allowing them certain flexibility.

Keywords: port labor, health/disease process, stevedores.

\section{Introdução}

Os portos surgiram da necessidade de exportação, movimentação de pessoas, armas e pelo comércio de mercadorias que ocorriam no litoral brasileiro durante o período colonial (FILHO, 2007). As transformações nos portos são associadas ao encurtamento de distâncias, a agilidade, a melhora na infra-estrutura dos navios e a um menor gasto em fretes, favorecendo a relação entre homens, mercadorias e informações (MONIÉ e VIDAL, 2006). Dentre os diversos trabalhadores que estão inseridos nos portos os trabalhadores portuários avulsos são aqueles que prestam serviços de forma eventual, sem vínculo empregatício, para várias operadoras portuárias, as quais solicitam esse serviço ao Órgão de Gestão de Mão-de-obra do Trabalho Portuário Avulso (OGMO). O OGMO possui caráter administrativo, fiscalizador e profissionalizante (SOARES et al; 2008).

O trabalhador portuário avulso concorre à escala de trabalho que é rodiziária, porém, nem todos os trabalhadores são contemplados com oportunidades de trabalho (SOUZA, 2006). A movimentação de cargas (embarque ou desembarque), sua arrumação, transbordo, peação e despeação, bem como o carregamento e a descarga das mesmas, sendo realizadas com equipamentos de bordo e os rechegos a bordo realizadas nos porões e/ou conveses das embarcações é feita pelos trabalhadores da estiva.

Os estivadores são os trabalhadores responsáveis pela movimentação da mercadoria, trabalhando a bordo das embarcações e realizando atividades que incluem operação de equipamentos e manejo de cargas, que antigamente, era executada exclusivamente por trabalho braçal, ora que, nos dias atuais, conta com o apoio de maquinários apropriados para a realização da atividade como esteiras rolantes e guindastes, fazendo com que o trabalho braçal seja executado basicamente no momento de organizar as sacarias (MONIÉ e VIDAL, 2006; DIEGÚES, 2007). Esses trabalhadores estão expostos à 
problemas de saúde como doenças de pele, musculares e osteoarticulares, e ainda os distúrbios por esforços repetitivos (CAVALCANTE et al., 2005).

As afecções relacionadas ao sistema osteomuscular têm se tornado cada vez mais comuns, mundialmente, durante as últimas décadas e estão entre as mais importantes causas de morbidade e incapacidade em adultos (SOUZA et al., 2009).

No Brasil uma das principais doenças relacionadas ao trabalho são distúrbios osteomusculares relacionados ao trabalho (DORT). O referido quadro patológico afeta diversas categorias profissionais e apresenta uma considerável relevância social devido a sua abrangência e magnitude. É também responsável por grande parte dos gastos com tratamento de saúde e indenizações, sendo a segunda causa de afastamento do trabalho (FERNANDES, ROCHA e COSTA- OLIVEIRA, 2009).

Tem sido observado que saúde humana está sendo influenciada pelas transformações que o processo de globalização produz e a reestruturação produtiva vem desenhando o modo de vida e definindo outros padrões de saúde-doença das populações (AZAMBUJA, KERBER e KIRCHHOF, 2007). Portanto o processo saúde-doença compreende não somente as questões biológicas, mas também engloba diversos fatores entre eles os sociais e ambientais (ROUQUARYOL e FILHO, 2003).

O modelo de globalização levou ao processo de precarização do trabalho, tendo como consequência direta o aumento das funções e da jornada das atividades profissionais, além da maior exposição a fatores de riscos para a saúde, afetando de maneira complexa o estilo de vida e o padrão de saúde-doença dos trabalhadores (FERNANDES, ROCHA e COSTAOLIVEIRA, 2009).

Atualmente, os trabalhadores têm que se adaptar às tecnologias e se atualizar perante um mercado competitivo. Diante destas situações, o ser humano está envolvido num processo complexo e dinâmico que abrange as condições somáticas, os processos cognitivos e emocionais, e as questões sociais. Observa-se, então, que os trabalhadores são atingidos por estas transformações, que ocorrem num ritmo elevado, muitas vezes maior que a própria capacidade humana pode suportar (PESSOA et al., 2010).

A precarização do trabalho caracteriza-se por desregulamentação e perda de direitos trabalhistas e sociais, legalização dos trabalhos temporários e informais. Como consequência, o aumento no número de trabalhadores autônomos e subempregados, bem como a fragilização das organizações sindicais e das ações de resistência individuais e/ou coletivas dos sujeitos Divers@ Revista Eletrônica Interdisciplinar/Matinhos/Vol.5, n.2, p.1-136/jul./dez./2012 
sociais. Devido a isso, tem havido intensificação do trabalho, aumento da jornada, acúmulo de funções, maior exposição a fatores de risco para a saúde, descumprimento de regulamentos de proteção à saúde e à segurança, diminuição dos níveis salariais e aumento da instabilidade no emprego. Desta forma, visualiza-se uma modificação no perfil de adoecimento e sofrimento dos trabalhadores, traduzido em acidentes do trabalho e em doenças ocupacionais (AZAMBUJA, KERBER e KIRCHHOF, 2007).

Apoiadas no avanço científico-tecnológico e no mito da inesgotabilidade dos recursos naturais, as mudanças na organização e gestão do trabalho têm repercussões importantes sobre as condições de vida, o perfil de adoecimento e morte das pessoas, dos trabalhadores e de grupos sociais mais vulneráveis, e também sobre o ambiente, exigindo-se políticas públicas capazes de garantir vida e saúde para o ambiente e a população (DIAS, 2009).

Com o processo de modernização dos portos, a partir da implementação da Lei 8.630 de 25 de fevereiro de 1993 foram designadas mudanças no trabalho do trabalhador portuário, entre elas a flexibilidade na designação do trabalho, a chamada multifuncionalidade e distribuição do trabalho na forma de rodízio. A lei de modernização portuária pode ser dividida em três objetivos, a criação do OGMO, a abertura dos portos para a exploração da iniciativa privada quebrando assim o monopólio sindical e a implementação do conselho de autoridade portuária que é composto pelo poder público, operadores portuários e trabalhadores portuários (MONIÉ e VIDAL, 2006, DIEGÚES, 2007). O impacto dessas mudanças no processo e na organização do trabalho e suas implicações na saúde dos trabalhadores demandam maiores investigações. As novas características do trabalho incluem: diminuição do número de trabalhadores por equipe a intensificar a produtividade do trabalho, a extinção de algumas funções, o trabalho em turnos menores e noturnos, as exigências de maior qualificação, criação de uma nova categoria profissional (multifuncional). Essa nova configuração do trabalho se manifesta nas experiências de saúde, adoecimento e acidentes de trabalho (MACHIN, COUTO e ROSSI, 2009).

O processo de modernização dos portos se deu através da transformação de um mercado econômico que se tornou globalizado, essas transformações resultaram da necessidade de um aprimoramento técnico que alterou a dinâmica e as práticas no setor portuário e que passou a exigir novas habilidades para a atividade laboral, sendo assim, exigindo um novo perfil de trabalhador (AGUIAR, JUNQUEIRA e FREDDO, 2006). 


\section{Materiais e métodos}

O estudo caracteriza-se como exploratório, cuja análise de dados foi quantitativa e representa um recorte de um projeto de pesquisa mais amplo, o qual ainda está em andamento, portanto apresentam-se, nesta publicação, resultados parciais da pesquisa. Desenvolveu-se no Porto de Paranaguá/PR de dezembro de 2009 a maio de 2010. O estudo foi aprovado pelo Comitê de Ética em Pesquisa com Seres Humanos da Universidade Federal do Paraná, sob o registro CEP/SD: 816.151.09.10. Foram entrevistados 100 estivadores do sexo masculino, de um total de 1.500 cadastrados no Sindicato dos Estivadores dos Portos de Paranaguá e Antonina, caracterizados como trabalhadores portuários avulsos, com idade média de 47 anos. Os sujeitos foram identificados por números a fim de preservar a identidade dos mesmos e todos assinaram um termo de consentimento livre e esclarecido. A pesquisa de campo foi desenvolvida no espaço de recrutamento de estivadores, denominado 'ponto de chamada' e na clínica de saúde, denominada 'sindestiva'. Cada sujeito foi entrevistado e abordado individualmente pelas alunas de Iniciação Científica do projeto. A duração de cada entrevista era de cerca de 20 minutos. Como ferramentas utilizou-se um questionário denominado Perfil dos entrevistados (contendo informações pessoais, informações sobre o trabalho, qualidade do sono, prática de atividade física, saúde, riscos no trabalho e satisfação no trabalho), o Questionário Nórdico que avalia dores músculo esqueléticas (PINHEIRO, TRÓCOLLI e CARVALHO, 2002) e o questionário para avaliação do Risco de Lombalgia (COUTO, 1995).

\section{Resultados e discussão}

A idade mínima dos entrevistados foi de 30 anos e a idade máxima foi de 71 anos. Dos sujeitos entrevistados, $53 \%$ tinha o $2^{\circ}$ grau completo, $34 \%$ com $1^{\circ}$ grau completo, $6 \%$ com $2^{\circ}$ grau incompleto, $5 \%$ com $1^{\circ}$ grau incompleto e $2 \%$ com $3^{\circ}$ grau completo, como demonstrado no gráfico 1. O tempo médio de atuação na função de estivador era de 20 anos. 


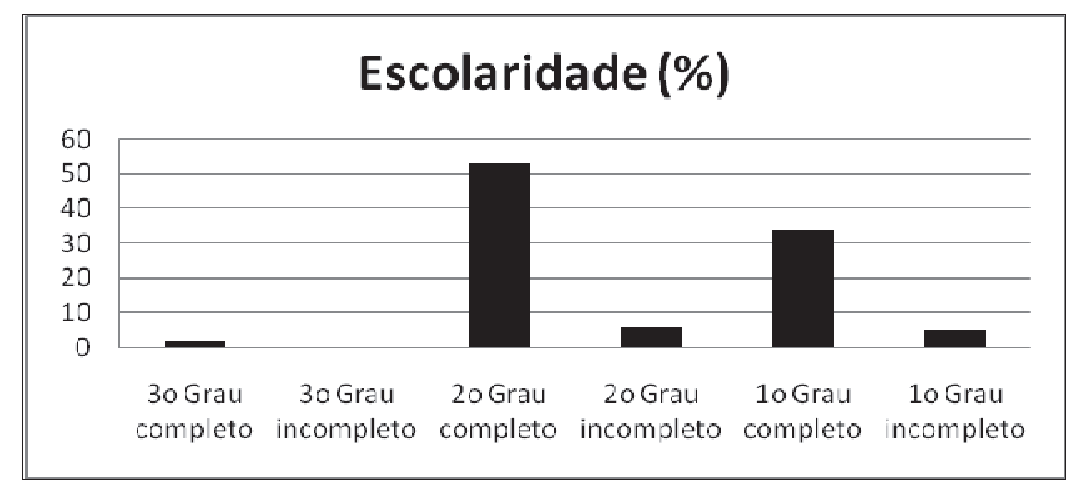

Gráfico 1 - Escolaridade dos trabalhadores portuários.

Os operadores entrevistados classificaram a qualidade do sono como sendo boa (51\%), ótima (34\%), ruim (12\%), regular (2\%) e péssima (1\%), como no gráfico 2. No artigo de revisão sistemática de Gemelli; Hilleshein e Lautert (2008), trabalhadores de indústria petroquímica, profissionais da saúde e caminhoneiros apresentaram, após o turno noturno, sono mais curto e de pior qualidade e menor estado de alerta quando comparados a eles mesmos e a outros trabalhadores, apesar de estarem expostos a diferentes estressores. Comparado aos resultados da qualidade do sono dos trabalhadores portuários percebe-se que em sua maioria, os trabalhadores portuários apresentam melhor qualidade do sono, isto se justifica, provavelmente, devido ao limite de horas de trabalho diário, que é de 6 horas, imposto pelo OGMO, proporcionando-lhes maior número de horas para descanso.

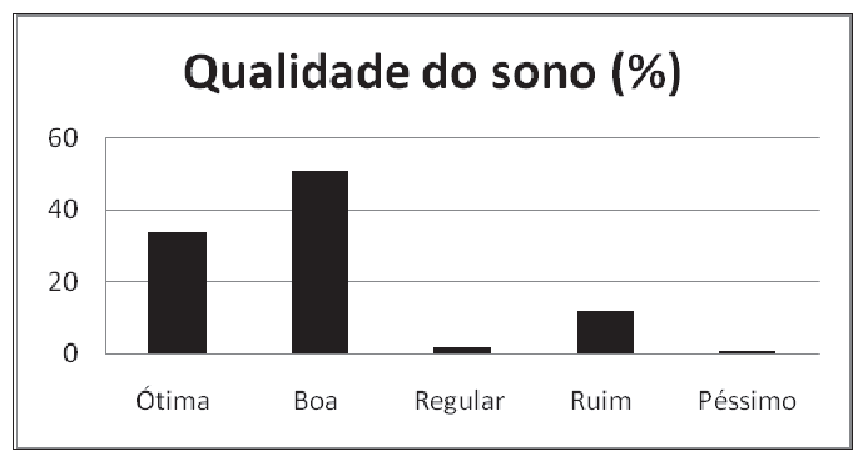

Gráfico 2 - Qualidade do sono dos trabalhadores portuários.

Houve predomínio de sujeitos que praticavam atividade física, sendo que 58\% relatam praticar e $42 \%$ não realizam nenhuma atividade física. No estudo de Martinez e Latorre (2008), boa parte dos eletricitários do estado de São Paulo (71,6\%) informou praticar algum Divers@ Revista Eletrônica Interdisciplinar/Matinhos/Vol.5, n.2, p.1-136/jul./dez./2012 
tipo de atividade física. O grande percentual de trabalhadores não sedentários nesta última pesquisa explica-se por existir um centro de atividades físicas na sede da empresa e ações de incentivo à prática de atividade física, e tratar-se de uma população relativamente jovem, onde a necessidade de bom preparo físico para atender às exigências físicas no trabalho dos eletricistas pode servir de estímulo à prática destas atividades visando preservar a qualificação para o desempenho do trabalho.

No caso dos trabalhadores portuários o maior número de praticantes de atividades físicas pode estar sendo influenciado por fatores semelhantes à dos eletricitários, ou seja, também possuem uma espécie de clube, que pode ser utilizada pelos trabalhadores e seus familiares e devido ao tipo de trabalho dos estivadores que exige bom preparo físico para atender às exigências físicas do trabalho para um melhor desempenho laboral.

Apesar dos dados sobre a prática de atividade física, ao serem questionados sobre problemas de saúde, houve predomínio de dores nas costas, totalizando $52 \%$ dos entrevistados, seguido de queixas de dores nos braços (26\%) e dor no pescoço (17\%). Esses dados são coerentes com a aplicação do questionário Nórdico, onde 56\% relatou sentir dor, formigamento/dormência nos últimos 12 meses na parte inferior das costas, $47 \%$ referiu esses sintomas nos joelhos e $43 \%$ na parte superior das costas, como apresentado no gráfico 3 :

\begin{tabular}{|c|c|c|c|c|}
\hline \multirow[t]{11}{*}{ REGIÃO CORPORAL } & & $\begin{array}{c}\text { Cltimos } \\
12 \text { meses } \\
(\%)\end{array}$ & $\begin{array}{c}\text { Ciltimos } \\
7 \text { dias } \\
(\%) \\
\end{array}$ & $\begin{array}{c}\text { Consultow } 1 \\
\text { profisional da saude } \\
\text { nos ulitimos } 112 \text { mese } \\
(\%) \\
(\%)\end{array}$ \\
\hline & SEM PROBLEMAS & 13 & 56 & 46 \\
\hline & OMBROS & 37 & 9 & 18 \\
\hline & PARTE SUPERIOR DAS COSTAS & 43 & 17 & 21 \\
\hline & COTOVELOS & 26 & 6 & 7 \\
\hline & PUNHOS/MÃOS & 40 & 13 & 14 \\
\hline & PARTE INFERIOR DAS COSTAS & 56 & 26 & 34 \\
\hline & QUADRIL/COXAS & 36 & 15 & 15 \\
\hline & JOELHOS & 47 & 19 & 22 \\
\hline & TORNOZELOS/PÉS & 36 & 13 & 14 \\
\hline & & & & \\
\hline
\end{tabular}

Gráfico 3 - Respostas do questionário nórdico dos trabalhadores portuários. 
No estudo de Célia e Alexandre (2004) ao analisar os trabalhadores do Serviço de Transportes de pacientes, que executam transportes intra e intermunicipais e que apresentaram sintomas osteomusculares nos últimos 12 meses, através do questionário nórdico, apresentaram prevalência de dor na parte inferior das costas, com 59\%, seguida de 49,2\% com dor, formigamento/dormência na parte superior das costas e $29,5 \%$ em tornozelos/pés. A partir destes dados, percebe-se o alto índice de dor na região das costas que prevalece em trabalhadores cujos trabalhos exigem grandes esforços físicos.

Apesar dos avanços tecnológicos com a modernização dos portos brasileiros, algumas tarefas desenvolvidas pelos estivadores exigem grandes esforços físicos, como por exemplo, quando trabalham na sacaria. Nessa atividade fazem carregamento manual de carga (cerca de $50 \mathrm{~kg}$ ), adotam posturas assimétricas e há repetitividade, embora o trabalho seja executado em dupla. As queixas e afastamentos só não são maiores, devido ao fato de que não fazem o mesmo trabalho diariamente, pois a cada jornada de trabalho desempenham tarefas em diferentes setores.

Com a aplicação do Questionário que avalia Risco de Lombalgia, verificou-se que $80 \%$ dos entrevistados têm altíssimo risco de lombalgia (gráfico 4), dado que também está de acordo com dos demais itens avaliados e citados anteriormente.

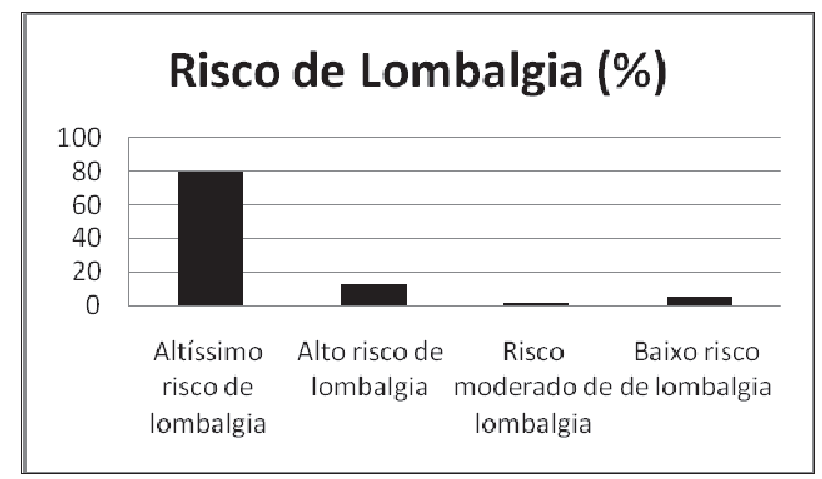

Gráfico 4 - Risco de lombalgia em trabalhadores portuários.

No estudo de Ribeiro, Tereso e Abrahão (2009), com trabalhadores de seis indústrias do setor metal-mecânico e de alimentos, foi observado que os trabalhadores relataram extremo desconforto em áreas do corpo com grande potencial de lesões osteomusculares quando muito exigidas, tais como a coluna lombar e sacral, os ombros e o pescoço. Esses 
fatores em seu conjunto apontam a necessidade urgente de modificação das tarefas nos postos. O trabalho destes envolvia: descarregamento, alimentação, paletização (um sistema utilizado para a movimentação e a otimização de cargas com o uso de empilhadeira ou garfo mecânico), pesagem e carregamento.

Desta maneira, percebe-se a semelhança na exigência de trabalho dos portuários e das indústrias do setor metal-mecânico e de alimentos, mostrando a necessidade de desenvolver tecnologias que minimizem os riscos de lesão do sistema osteomuscular dos trabalhadores que executam este tipo de tarefas, a fim de preservar a saúde dos operadores.

Quanto à percepção dos estivadores no que se refere aos principais riscos ocupacionais encontrados na rotina do trabalho portuário, os resultados mais apontados foram: trabalho em alturas (93\%), substâncias químicas no ar (93\%), ruídos (92\%), queda de objetos suspensos (89\%), tráfego de máquinas (89\%) e deslocamento do trabalhador sobre as cargas (89\%), como no gráfico 5.

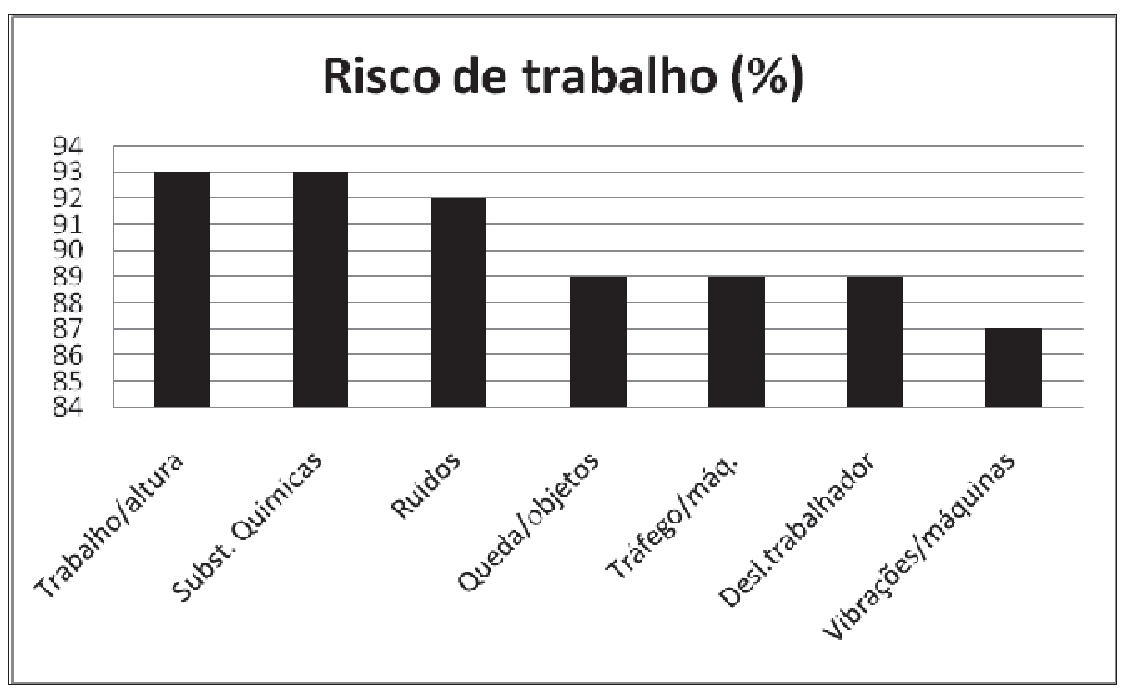

Gráfico 5 - Respostas em relação aos maiores riscos de trabalho considerados pelos trabalhadores portuários.

Na pesquisa de Iriart et al. (2008), com trabalhadoras domésticas e trabalhadores da construção civil, em relação à consciência dos riscos no trabalho, as primeiras perceberam os riscos de acidente no trabalho doméstico de forma diversa. Para algumas, transparece a dificuldade de conceber o ambiente de trabalho e as atividades desempenhadas como portadoras de riscos de acidentes, dada a similaridade com as atividades desenvolvidas em suas próprias casas. A casa é percebida, antes de tudo, como um espaço seguro, o que a Divers@ Revista Eletrônica Interdisciplinar/Matinhos/Vol.5, n.2, p.1-136/jul./dez./2012 
diferencia das empresas e indústrias, essas sim, espaços permeados por fatores de risco de acidentes. Já para os trabalhadores da construção civil, a consciência dos riscos de acidentes presentes no trabalho é muito forte.

Foram identificados riscos diversos, tais como: ser atingido por objetos, carregar peso, contato com substâncias tóxicas e objetos pérfuro-cortantes, além do risco de queda. Entre os problemas de saúde decorrentes do trabalho, foram citados os de coluna, os respiratórios em consequência da inalação de poeira e cheiro de tinta, hérnia, dores musculares, dores nas pernas e corrosão das mãos na manipulação de cimento. Outros riscos citados foram trabalhar em ambiente insalubre e em local inseguro (sujeito a deslizamento de terra).

Portanto, a percepção quanto aos riscos no trabalho varia de acordo com a função e local de trabalho. Diferentemente do trabalho das empregadas domésticas, os trabalhadores portuários aparentemente executam maior esforço físico e é um local muito diferente de suas próprias casas, consideradas "seguras" pelas trabalhadoras. O autor Dejours (1992) identifica esse processo como um mecanismo de defesa psíquica frente às condições agressivas do trabalho. O mesmo argumenta que esses trabalhadores têm consciência dos riscos a que estão expostos, porém, como as medidas de proteção não os evitam totalmente, terminam por dispensá-las para não carregar um símbolo concreto dos perigos presentes no seu trabalho.

E em relação ao trabalho civil, este apresenta algumas características semelhantes, como, por exemplo, carregamento de peso, exposição à substâncias tóxicas e risco de queda, sendo percebido como um trabalho de alto risco, assim como o trabalho dos estivadores.

Ao serem questionados sobre qual o setor em que preferem trabalhar e qual a justificativa, verificou-se preferência pelo trabalho na operação de máquinas, que parece estar relacionado ao menor esforço físico e o trabalho com sacaria, ou seja, o trabalho no transporte de sacos de mercadorias. Percebeu-se que os sujeitos que preferem trabalhar na sacaria, o fazem por gerar melhor remuneração salarial, sujeitando-se a sacrificar-se fisicamente.

O gosto pelo trabalho portuário tem relação com o fato de não ser um trabalho monótono, por ser um trabalho que possibilita certa autonomia e liberdade e por ser um trabalho que garante o sustento da família. Conforme se verificou no estudo de Machin, Couto e Rossi (2009) realizado no porto de Santos, a inexistência de rotina, a liberdade do exercício de trabalho e a oportunidade de fazer seu próprio salário foram citados pelos trabalhadores como fatores de satisfação no seu trabalho. 
No estudo de Trindade et al. (2007) com agentes comunitários de saúde, estes consideram o trabalho monótono e repetitivo, podendo representar uma carga psíquica, segundo eles, devido à falta de liberdade para desenvolver novos projetos e tomar iniciativas para organizar o trabalho, atribuída ao autoritarismo de alguns profissionais da equipe de saúde. Assim, verifica-se que a monotonia do trabalho proporciona maior insatisfação profissional, quando há falta de liberdade para desenvolver novos projetos e tomar iniciativas para organizar o trabalho, ocorrendo de maneira diferente no trabalho portuário, onde o trabalhador consegue de certa forma escolher ou, no caso, excluir as funções das quais são de menor gosto, e desta forma, organizar o seu próprio trabalho.

\section{Conclusões}

Os trabalhadores portuários estudados apresentam grande variabilidade de idade e a maioria deles possui vários anos de atividade na função de estivador. Apesar dos dados sobre a prática de atividade física, ao serem questionados sobre problemas de saúde, houve predomínio de dores nas costas, seguido de queixas de dores nos braços e dor no pescoço. Esses dados são coerentes com a aplicação do questionário Nórdico, onde $56 \%$ relatou sentir dor, formigamento/dormência na parte inferior das costas, $47 \%$ referiu esses sintomas nos joelhos e $43 \%$ na parte superior das costas. Os casos de adoecimento e afastamento do trabalho por queixas dolorosas só não foram maiores devido a multifuncionalidade dos estivadores, o que possibilita mudança de gestos, posturas e movimentos a cada jornada de trabalho.

Com a modernização dos portos, os operadores portuários convivem com a tecnologia ao mesmo tempo em que executam tarefas braçais, como por exemplo o transporte de mercadorias em sacos (sacaria), o que justifica também as dores musculoesqueléticas, principalmente de região lombar. A configuração atual do trabalho portuário leva os operadores a sobrecarga física e mental, uma vez que existe um preocupação com o aumento dos rendimentos financeiros aliada à uma exposição corporal cada vez maior.

Os resultados encontrados no estudo permitem a elaboração de estratégias de promoção de saúde para os operadores portuários, particularmente para os estivadores e a divulgação junto aos órgãos competentes sobre a importância de preservar a saúde dessa população, a qual participa no desenvolvimento econômico do país.

Divers@ Revista Eletrônica Interdisciplinar/Matinhos/Vol.5, n.2, p.1-136/jul./dez./2012 


\section{Referências}

AGUIAR, A. P. F.; JUNQUEIRA, L.A.P.; FREDDO, A.C.M. O Sindicato dos Estivadores do Porto de Santos e o processo de modernização portuária. Rap, Rio de Janeiro, v. 40, n.6, p. 997-1017,2006.

AZAMBUJA, E.P.; KERBER, N.P.C.; KIRCHHOF, A.L. A saúde do trabalhador na concepção de acadêmicos de enfermagem. Rev. esc. Enferm USP, São Paulo, v.41, n.3, p. 355-62,2007.

BRASIL. Lei $\mathbf{n}^{\mathbf{0}} \mathbf{8 6 3 0}$, de 25 de fevereiro de 1993. Dispõe sobre o regime jurídico da exploração dos portos organizados e das instalações portuárias e dá outras providências. (LEI DOS PORTOS). Diário Oficial da União de 26 de fevereiro de 1993, pág, 2351.

CAVALCANTE, F.F.G.; et al. Estudo sobre os riscos da profissão de estivador do Porto do Mucuripe em Fortaleza. Ciênc. saúde coletiva. v.10, n.0, p. 101-110,2005 2005.

CÉLIA, R.C.R.S.; ALEXANDRE, N.M.C. Aspectos ergonômicos e sintomas osteomusculares em um setor de transporte de pacientes. Rev Gaúcha Enferm, Porto Alegre (RS), v.25, n.1, p. 33-43, 2004.

COUTO, H.A. Ergonomia aplicada ao trabalho: o manual técnico da máquina humana. Belo Horizonte: Ergo, 1995. vol.1.

DEJOURS, C. A loucura do trabalho: estudo de psicopatologia do trabalho. São Paulo: Cortez-Oboré, 1992.

DIAS, E.C. Novas possibilidades para o cuidado da Saúde do Trabalhador e da Saúde Ambiental na Atenção Básica do SUS. Ciênc. saúde coletiva, Rio de Janeiro, v.14, n. 6 , 2009.

DIEGUÉZ, C.R.M.A. De OGMO (Operário Gestor de Mão de Obra) para OGMO (Órgão Gestão de Mão de Obra): modernização e cultura do trabalho no porto de Santos. 2007. Dissertação (mestrado em Sociologia). Faculdade de Filosofia, Letras e Ciências Humanas da Universidade de São Paulo, 2007.

FERNANDES, M.H.; ROCHA, V.M.; COSTA-OLIVEIRA, A.G.R. Fatores Associados à Prevalência de Sintomas Osteomusculares em Professores. Rev. Saúde Pública, São Paulo, v.11, n.2, p. 256-267, 2009.

FILHO, A.G. Melhoramentos, reaparelhamentos e modernização dos portos brasileiros: a longa e constante espera. Economia e Sociedade, Campinas, v. 16, n. 3, p. 455-489, 2007. 
GEMELLI, K.K.; HILLESHEIN, E.F.; LAUTERT, L. Efeitos do trabalho em turnos na saúde do trabalhador: revisão sistemática. Rev Gaúcha Enfermagem, Porto Alegre (RS), v.29, n. 4, p. 639-46, 2008.

IRIART, J.A.B.; et al. Representações do trabalho informal e dos riscos à saúde entre trabalhadoras domésticas e trabalhadores da construção civil. Ciênc. saúde coletiva, Rio de Janeiro, v.13, n.1, p.165-174, 2008.

MACHIN, R.; COUTO, M.T.; ROSSI, C.C.S. Representações de Trabalhadores Portuários de Santos-SP sobre a Relação Trabalho-Saúde. Saúde Soc, São Paulo, v.18, n.4, p.639-651, 2009.

MARTINEZ, M.C.; LATORRE, M.R.D.O. Saúde e capacidade para o trabalho de eletricitários do estado de São Paulo. Ciência \& Saúde Coletiva, Rio de Janeiro, v.13, n.3, p. 1061-1073, 2008.

MONIÉ, F.; VIDAL, S.M.S.C. Cidades, port MOTTER; NISHIZUKA; GONÇALVES; et al produtiva. RAP, Rio de Janeiro, v.40, n. 6, p. 9' וオン, ムvvu.

PESSOA, J.C.S.; et al. Análise das limitações, estratégias e perspectivas dos trabalhadores com LER/DORT, participantes do grupo PROFIT-LER: um estudo de caso. Ciênc. Saúde Coletiva, Rio de Janeiro, v.15, n. 3, p. 821-830, 2010.

PINHEIRO, F.A.; TRÓCCOLI, B.T.; CARVALHO, C.V. Validação do questionário nórdico de sintomas osteomusculares como medida de morbidade. Revista de Saúde Pública, São Paulo, v. 36, n.3, p. 307-312, 2002.

RIBEIRO, I.A.V.; TERESO, M.J.A.; ABRAHÃO, R.F. Análise ergonômica do trabalho em unidades de beneficiamento de tomates de mesa: movimentação manual de cargas. Cienc. Rural, Santa Maria, v.39, n. 4, p. 821-830 , 2009.

ROUQUARYOL,M.Z.; FILHO, N.A. Epidemiologia e saúde. $6^{\text {a }}$ edição, Rio de Janeiro: Editora Guanabara Koogan, 2003.

SOARES, J.F.S.; et al. Percepção dos trabalhadores avulsos sobre os riscos ocupacionais no porto do Rio Grande, Rio Grande do Sul, Brasil. Cad. Saúde Pública, Rio De Janeiro, v. 24, n. 6, p. 1251-1259, 2008.

SOUZA, A.C.; et al. Sintomas osteomusculares em trabalhadores da enfermagem: uma revisão integrativa. Cienc. Cuid. Saude, São Paulo v.8, n.4, p. 683-690, 2009.

SOUZA, M.V.L. Trabalho avulso. Porto de Paranaguá. Escala Eletrônica. Intervalo entre jornadas. Renda mínima. Greve.

Disponível em: <http://jus2.uol.com.br/doutrina/texto.asp?id=8732>. Acesso em: 10 fev. 2010.

TRINDADE, L.L.; et al. Cargas de trabalho entre os agentes comunitários de saúde. Rev Gaúcha Enferm, Porto Alegre (RS), v.28, n. 4, p. 473-9, 2007.

Divers@ Revista Eletrônica Interdisciplinar/Matinhos/Vol.5, n.2, p.1-136/jul./dez./2012 